\title{
Experimental Investigation of the Propeller Design for future QESTOL Aircraft in the BNF Project
}

\author{
Carsten Lenfers* \\ Ruud F. Janssen ${ }^{\dagger}$ \\ Nils Beck $k^{\ddagger}$ \\ Jens Friedrichs ${ }^{\S}$ \\ Alireza Rezaeian
}

Due to increasing airport congestion the German research project 'Bürgernahes Flugzeug' (BNF, citizen friendly airplane) investigates the potential of aircraft concepts for a possible future air transportation system integrating small airports. Key technologies in aerodynamics for developing new generation quiet, efficient, short take-off and landing (QESTOL) aircraft are studied through the synergistic exploitationof Computational Fluid Dynamics (CFD) and new wind tunnel data. One subject of the conducted investigations is a ninebladed high power propeller mounted in tractor configuration on a wing that is equipped with an active gapless high-lift system. As the aerodynamic focus of the BNF project is on the interaction between the propeller slipstream and the high-lift flowfield, this paper is focussed on the experimental investigation of the propeller performance in comparison with simulation data.

\section{Nomenclature}

$b \quad$ Wingspan, $[m]$

$B E T$ Blade element theory

$B N F$ Bürgernahes Flugzeug, (citizen friendly aircraft)

$c \quad$ Chord length, $[m]$

$C_{L} \quad$ Aircraft lift coefficient, $[-]$

$c_{l} \quad$ Airfoil lift coefficient, $[-]$

$C_{P} \quad$ Power coefficient, $[-], C_{P}=\frac{P}{\rho \cdot n^{3} \cdot D^{5}}$

$C_{T} \quad$ Thrust coefficient, [-], $C_{T}=\frac{T}{\rho \cdot n^{2} \cdot D^{4}}$

$C F D$ Computational Fluid Dynamics

$D$ Propeller diameter, $[m]$

DLR Deutsches Zentrum für Luft- und Raumfahrt (German Aerospace Center)

$J \quad$ Advance ratio, $[-], J=\frac{v_{\infty}}{n \cdot D}$

$k \quad$ Scaling factor, $[-]$

$M \quad$ Freestream Mach number, $[-]$

$M_{H} \quad$ Helical blade tip Mach number, [-]
MTOM Maximum take off mass, $[\mathrm{kg}]$

$n \quad$ Propeller rotational speed, $\left[\frac{1}{s}\right]$

$P \quad$ Power, $[k W]$

$Q \quad$ Torque, $[\mathrm{Nm}]$

QESTOL Quiet efficient short take-off and landing

RANS Reynolds-averaged Navier-Stokes (equations)

STOL Short take-off and landing

$T$ Thrust, $[N]$

$v_{\infty} \quad$ Freestream velocity, $\left[\frac{\mathrm{m}}{\mathrm{s}}\right]$

$v_{\text {eff }} \quad$ Effective velocity $\left[\frac{m}{s}\right]$

$w / t \quad$ Wind tunnel

$w_{i} \quad$ Induced velocity, $\left[\frac{m}{s}\right]$

$y^{+} \quad$ Non-dimensional wall distance, $[-]$

Subscripts

cr Cruise conditions

$\max$ Maximum

to $\quad$ Take-off conditions

${ }^{*}$ Research Scientist, German Aerospace Center (DLR), Institute of Aerodynamics and Flow Technology, Lilienthalplatz 7 , 38108 Braunschweig, Germany.

†Student of Faculty of Aerospace Engineering, Delft University of Technology, Kluyverweg 1, 2629 HS Delft, Netherlands.

${ }^{\ddagger}$ Research Scientist, Technical University of Braunschweig, Institute of Fluid Mechanics, Hermann-Blenk-Strasse 37, 38108 Braunschweig, Germany.

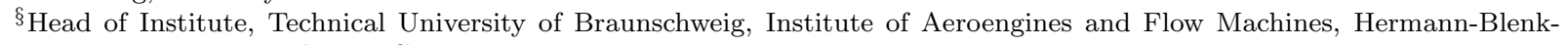
Strasse 37, 38108 Braunschweig, Germany.

『Research Scientist, German Aerospace Center (DLR), Institute of Aeroelasticity, Bunsenstrasse 10, 37073 Göttingen, Germany. 
Symbols

$\alpha \quad$ Angle of attack, propeller axis inclination, $\left[{ }^{\circ}\right]$

$\beta_{75}$

$\eta$
Blade pitch angle at $75 \%$ radius, $\left[^{\circ}\right]$ Efficiency, [-]
$\Lambda$

$\rho$

$\varphi$
Wing aspect ratio , $[-]$

Density, $\left[\frac{\mathrm{kg}}{\mathrm{m}^{3}}\right]$

Wing sweep angle, $\left[^{\circ}\right]$

\section{Introduction}

In future decades a continuous demand for of affordable, sustainable, reliable and seamless mobility will lead to increasing airport congestion ${ }^{1234}$ and it is imperative that additional capacities have to be made available. As most of the European major hubs are subject to environmental or residential constraints their extension or even the new construction seems to be an unlikely way to cope with these challenges of the future air transportation concept. One reasonable concept is the integration of existing regional airports into the air transportation concept. ${ }^{5}$ Considering todays fleet mix and its predicted development (see figure 1) the expected increase in the number of aircraft would result in a large growth in capacity requirements at existing large airports, since the limited runway length at regional airfields would preclude them from accepting traditional aircraft. This is neither an economically nor an ecologically acceptable solution. Due to historic development in urban settlement the residential areas are moved towards these small airfields. Therefore the aircraft operating there will underlie strict noise and emission regulations. Thus, it becomes mandatory that new aircraft has to be developed to cope with the depicted challenges of the future air transportation concept.

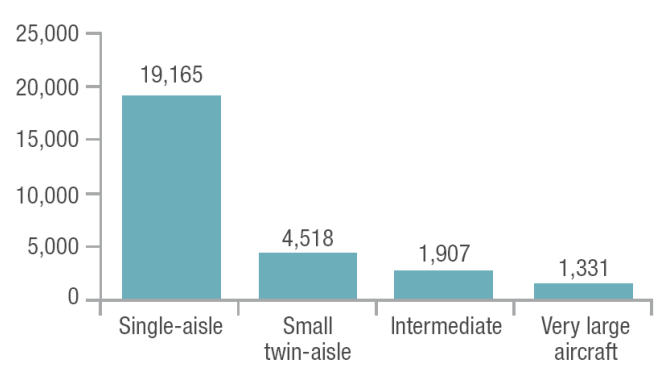

Figure 1. Demand of new aircraft in the period of 2010 to 2030,26900 aircraft in total. ${ }^{1}$

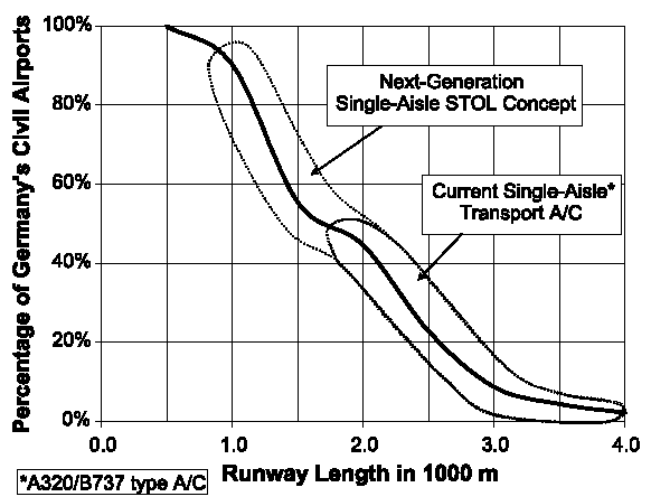

Figure 2. Composition of runway lengths in Germany. ${ }^{5}$

The new aircraft design has to provide STOL capabilities as well as sufficient capacity to gain a high passenger load per airfield. The impact of STOL capabilities is illustrated in figure 2. It predicts that aircraft with STOL capabilities to be able to depart at nearly $90 \%$ of german airfields.

The German research project 'Bürgernahes Flugzeug (BNF)' (citizen friendly airplane) is dedicated to make the key technologies to develop new QESTOL aircraft available. This project is partly funded by the federal state of Lower Saxony and conducted by the Technical University of Braunschweig, Leibniz University of Hannover and the German Aerospace Center (DLR). The aerodynamic scope is a generic QESTOL configuration as depicted in figure 3, that is investigated concerning its aerodynamic performance using high fidelity unsteady Reynolds-Averaged-Navier-Stokes (uRANS) computations as well as wind tunnel measurements. The aerodynamic focus is on the interaction of the propeller slipstream with the flowfield around an active gapless high-lift system.

This paper concentrates on the propeller performance of the investigated $\mathrm{w} / \mathrm{t}$ model. After a brief description of the propeller design and the experimental setup in the $\mathrm{w} / \mathrm{t}$, a detailed aerodynamic performance analysis is provided relying on experimental as well as on simulation data.

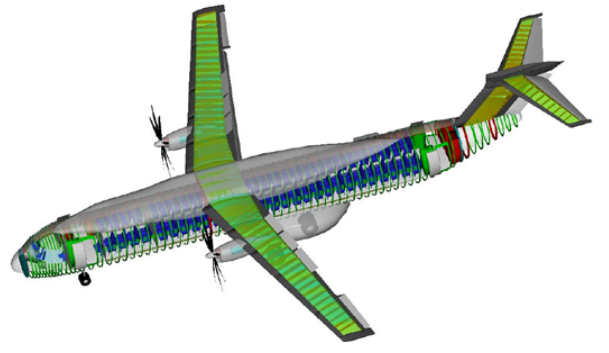

Figure 3. configuration of possible future QESTOL aircraft. ${ }^{6}$ 


\section{Propeller Design}

The detailed process of the conducted propeller design is described $i^{7}$ and is briefly summarized in this part. The BNF project utilises a generic twin engine single-aisle aircraft to assess the needed amount of take-off thrust and lift coefficient. Table 1 summarizes the aircraft data obtained by preliminary aircraft and propulsion system design. The main driver to obtain STOL capabilities, as defined in, ${ }^{8}$ are the take-off thrust and the high-lift performance. For the BNF configuration the enormous amount of lift during take-off is obtained by an active gapless high-lift system that utilises the coanda effect ${ }^{9} .{ }^{10}$

\begin{tabular}{|c|c|}
\hline$M T O M[k g]$ & 73000 \\
\hline$b[m]$ & 34.0 \\
\hline$\Lambda[-]$ & 9.3 \\
\hline$C_{L}[-]$ & 3.8 \\
\hline$M_{c r}[-]$ & 0.65 \\
\hline$v_{\infty_{t o}}\left[\frac{m}{s}\right]$ & 51.0 \\
\hline$T_{t o}[N]$ & 140000 \\
\hline$P_{t o}[k W]$ & 11800 \\
\hline$T_{c r}[N]$ & 20000 \\
\hline$D[m]$ & ca. 6.0 \\
\hline$n_{t o}\left[\frac{1}{\min }\right]$ & ca. 800 \\
\hline$M_{H_{t o}}[-]$ & $\leq 0.75$ \\
\hline$M_{H_{c r}}[-]$ & $\leq 1.00$ \\
\hline
\end{tabular}

Table 2. propeller performance data according to BET analysis.

\begin{tabular}{l|rr}
\hline \hline & cruise & take-off \\
\hline$T[N]$ & 20000.00 & 140000.00 \\
$P[k W]$ & 4732.00 & 16542.00 \\
$\eta[-]$ & 0.81 & 0.43 \\
$n\left[\frac{1}{\min }\right]$ & 700.00 & 793.60 \\
$v_{\infty}\left[\frac{\mathrm{m}}{\mathrm{s}}\right]$ & 192.00 & 51.00 \\
$M[-]$ & 0.65 & 0.15 \\
$M_{H}[-]$ & 0.99 & 0.75 \\
$\beta_{75}\left[^{\circ}\right]$ & 52.50 & 32.00 \\
\hline \hline
\end{tabular}

Based on the data listed in table 1 the propeller is designed with a blade element theory (BET) code developed by Martin Hepperle. ${ }^{11}$ This code uses the methods published by Adkins ${ }^{12}$ and Larrabee ${ }^{13}$ to gain a propeller design operating with a minimum of induced losses in certain design points. During the design process aerodynamic as well as aeroacoustic constraints were taken into account. Numerous parameter studies concerning number of blades, propeller diameter, helical blade tip Mach number and blade sweep angle distribution were conducted. The propeller performance data for cruise and take-off design point obtained with blade element theory is listed in table 2 .

As the BET does not take into account three dimensional effects, the obtained blade design is verified by means of Reynolds-averaged-Navier-Stokes (RANS) computations. A comparison of propeller performance data obtained by BET and RANS simulations is shown in figure 4. The design point for take-off is marked by a dashed black line. A very good correspondence between the obtained results can be found for the design point, with larger discrepancies found at off-design conditions. One possible explanation for these larger differences could be related to the behavior of the boundary layer of rotating systems as described in ${ }^{14} \cdot{ }^{15}$

To fit the cross section of the $\mathrm{w} / \mathrm{t}$, the size of the $\mathrm{w} / \mathrm{t}$ model is limited and therefore the diameter of the propeller. The propeller is scaled by $k=\frac{1}{9}$ considering aerodynamic and aeroacoustic similarity. Aerodynamic similarity is obtained by geometrical similarity and keeping the helical blade tip Mach number $M_{H}$ constant. The helical blade tip Mach number is defined as vector addition of the freestream Mach number parallel to the propeller axis and the Mach number resulting from rotation at the blade tip. Aeroacoustic similarity is obtained by keeping the Helmholtz number constant. The Helmholtz number describes the ratio of a characteristic length of the model to the sonic wavelength. For a more detailed description

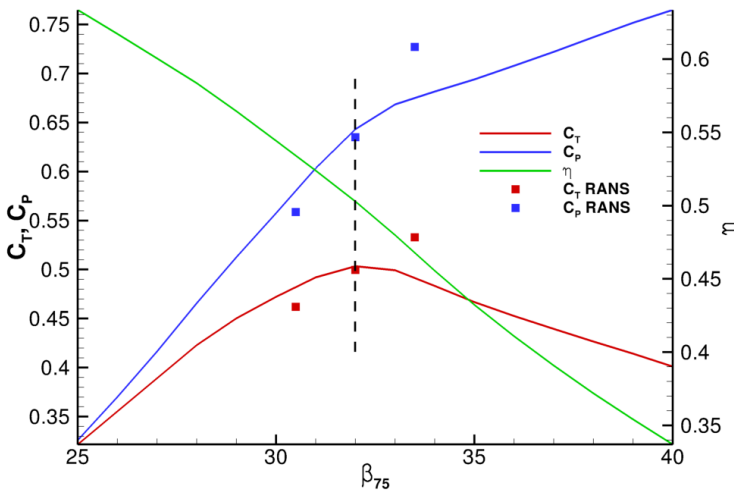

Figure 4. Comparison of propeller performance calculated by BET and RANS at take off conditions: $T_{t o}=138804 \mathrm{~N}, \rho_{t o}=1.225 \mathrm{~kg} / \mathrm{m}^{3}, M_{t o}=0.15$. 
of the scaling process see. ${ }^{7}$ The scaled propeller is integrated in tractor configuration with a semispan wing and investigated in a low speed $\mathrm{w} / \mathrm{t}$.

\section{Experimental Setup}

The aerodynamic experiments studying the interaction of the propeller slipstream and the high-lift flowfield are conducted in the low speed facility DNW-NWB. This w/t provides a closed test section with a cross section of $3.25 \mathrm{~m} \cdot 2.80 \mathrm{~m}$ and a maximum wind speed of $v_{w / t}=90.0 \mathrm{~m} / \mathrm{s}$.

The $\mathrm{w} / \mathrm{t}$ model consists of a semispan wing and the described propeller mounted in tractor configuration and driven by an electric motor. The setup inside the closed test section is shown in figure 5 . The aerodynamic design of the wing is conducted by the 'Institute of Fluid Mechanics' of the Technical University of Braunschweig.

The planform of the wing and the basic dimensions are depicted in figure 7 while the cross section can be seen in figure 6 . The wing is rectangular with a constant chord length of $c=0.5 \mathrm{~m}$ and a semispan of $b=1.7 \mathrm{~m}$. It is swept back by $\varphi=$ $10^{\circ}$. By scaling the original propeller to $\mathrm{w} / \mathrm{t}$ size its diameter $D=0.66 \mathrm{~m}$. In figure 6 the height of the slit of the active high-lift system can be seen and it equals $0.0006 \cdot c=0.0003 \mathrm{~m}$. This huge differences in length scales call for a highly accurate manufacturing process. The detailed description of the model construction can be found in ${ }^{16} \cdot{ }^{17}$

As the conducted work in the BNF project concentrates on the interaction between the propeller slipstream and the highlift flowfield, it is desirable to be able to position the propeller at different lateral, angular and vertical distances in front of the wing. Research activities conducted by the 'Institute of Aeroengines and Flow Machines' of the Technical University of Braunschweig revealed an electric motor to have an edge over pneumatic or hydraulic engines concerning flexibility in installation. ${ }^{18}$ Despite this flexibility another challenge concerning the propulsion system is the high power density that is needed to drive the propeller in its take-off operating point while min-

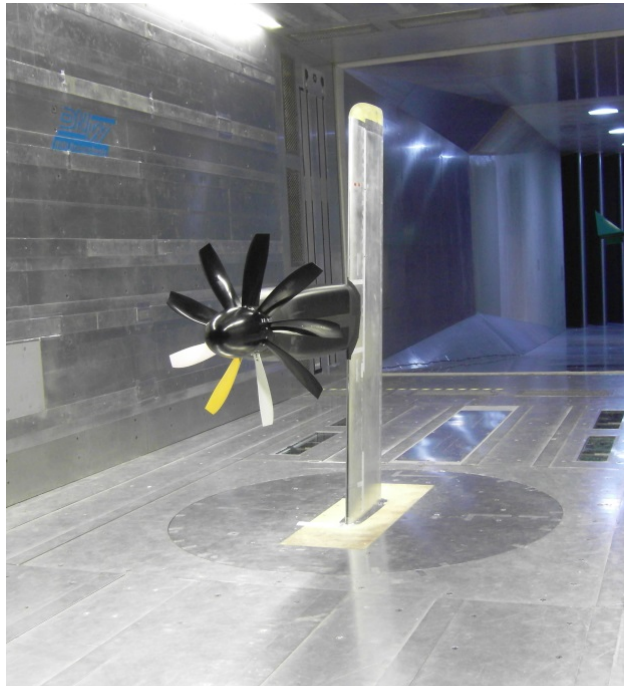

Figure 5. experimental setup in test section of DNW-NWB. imizing the flow displacement by the engine and its nacelle. The performance data of the propeller in its take-off design point at $\mathrm{w} / \mathrm{t}$ scale are shown in table 3 . A maximum delivered power of $174 \mathrm{~kW}$ was measured during the conducted $\mathrm{w} / \mathrm{t}$ test campaigns. Due to this high power consumption, the propeller delivered a thrust of about $1880 \mathrm{~N}$ while rotating with a rotational frequency of $n=67601 / \mathrm{min}$.

The wing is instrumented with pressure taps as well as time accurate acoustic pressure transducers. The pressure taps are arranged in four sections in line of flight and one row on the suction side of the wing in

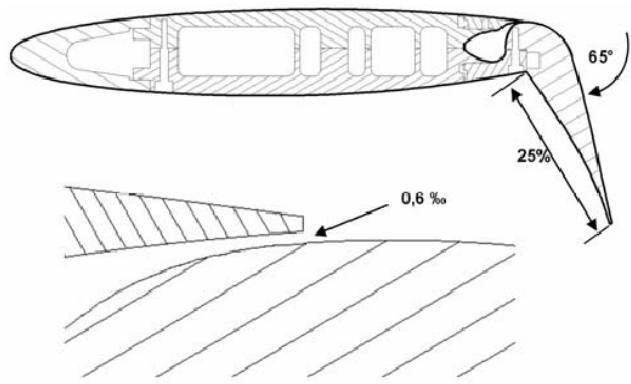

Figure 6. cross section.

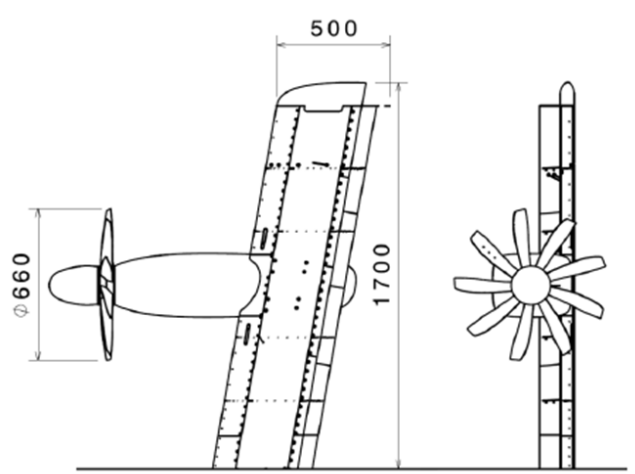

Figure 7. planform. 
Table 3. Data for the propeller in $\mathrm{w} / \mathrm{t}$-scale in the take-off design point.

\begin{tabular}{l|l}
\hline \hline$k[-]$ & $\frac{1}{9}$ \\
$D_{w t}[m]$ & 0.667 \\
$T_{t o_{w t}}[N]$ & 1700 \\
$Q_{t o_{w t}}[N m]$ & 233.1 \\
$n_{t o_{w t}}\left[\frac{1}{\mathrm{~min}}\right]$ & 7143.6 \\
$P_{t o_{w t}}[\mathrm{~kW}]$ & 175 \\
\hline \hline
\end{tabular}

Table 4. position of unsteady pressure probes.

\begin{tabular}{ccc}
\hline \hline pressure side & $0.55 \cdot R$ & $0.1 \cdot c$ \\
& $0.65 \cdot R$ & $0.1 \cdot c$ \\
& $0.75 \cdot R$ & $0.1 \cdot c$ \\
suction side & $0.60 \cdot R$ & $0.4 \cdot c$ \\
& $0.70 \cdot R$ & $0.4 \cdot c$ \\
& $0.80 \cdot R$ & $0.4 \cdot c$ \\
\hline
\end{tabular}

spanwise direction. Besides a measurement system for propeller thrust and torque, one propeller blade is equipped with six time accurate pressure taps - their positions on the surface of the blade are listed in table 4 . The thrust, torque and pressure data are transferred wirelessly from the rotating to the fixed frame by means of a telemetrie unit. During the $\mathrm{w} / \mathrm{t}$ tests the flutter behaviour is monitored simultaneously. Therefore, at several positions inside the wing and at certain positions on the propulsion system accelerometers are installed. Details of the installation, the online monitoring system and the concluded results can be found in ${ }^{1920} .^{21}$ As this paper focusses on the the propeller, the obtained wing-specific results of the conducted test campaigns can be found in. ${ }^{22}$

\section{Experimental results}

In this section an overwiev over obtained time averaged $\mathrm{w} / \mathrm{t}$ results is given. The presented data in this section is averaged over $850 \ldots 1200$ rotations depending on the investigated rotational frequency. Since resonance effects between the model eigenfrequencies and the rotational frequencies have to be avoided only specific combinations of freestream velocity $v_{\infty}$ and rotational frequency $n$ are investigated. The range of investigated advance ratios $J$ and the corresponding values for $v_{\infty}$ as well as $n$ are listed in table 5 .

\begin{tabular}{ccc}
\hline \hline$J[-]$ & $n\left[\frac{1}{\min }\right]$ & $v_{\infty}\left[\frac{m}{s}\right]$ \\
0.30 & 6006.0 & 20.0 \\
0.35 & 6435.0 & 25.0 \\
0.40 & 6757.0 & 30.0 \\
0.45 & 6006.0 & 30.0 \\
0.55 & 6552.0 & 40.0 \\
0.60 & 6006.0 & 40.0 \\
0.65 & 7069.0 & 51.0 \\
0.70 & 6564.0 & 51.0 \\
0.75 & 6126.0 & 51.0 \\
0.80 & 5743.0 & 51.0 \\
0.85 & 5405.0 & 51.0 \\
0.90 & 5105.0 & 51.0 \\
0.95 & 5690.0 & 60.0 \\
1.00 & 5405.0 & 60.0 \\
\hline \hline
\end{tabular}

Table 5. Invstigated advance ratios, corresponding freestream velocities and rotational frequencies

Figure 8 depicts the development of the thrust coefficient $C_{T}$ on the vertical axis, over the investigated range of advance ratios $J$ on the horizontal axis. Four datasets with different blade pitch angles $\beta_{75}$ are presented. The circular symbols depict the measured datapoint while the curves are interpolated using the measured datapoints. A vertical dash dotted line symbolizes the take off design point of the BNF propeller. Figure 8 reveals an almost linear trend for $C_{T}$ with increasing values of $J$. For all depicted blade pitch angles $\beta_{75}$, the behaviour of $C_{T}$ differs from the mentioned linear slope with decreasing advance ratio $J$. The point 
at which the deviation from a linear slope occurs, can be identified via the dash dotted tangential lines for the blade pitch angles of $\beta_{75}=28^{\circ}$ and $\beta_{75}=30^{\circ}$. For $\beta_{75}=28^{\circ}$ an advance ratio of $J=0.6$ and for $\beta_{75}=30^{\circ}$ an advance ratio of $J=0.64$ can be derived as the value for the lower bound of the linear slope.

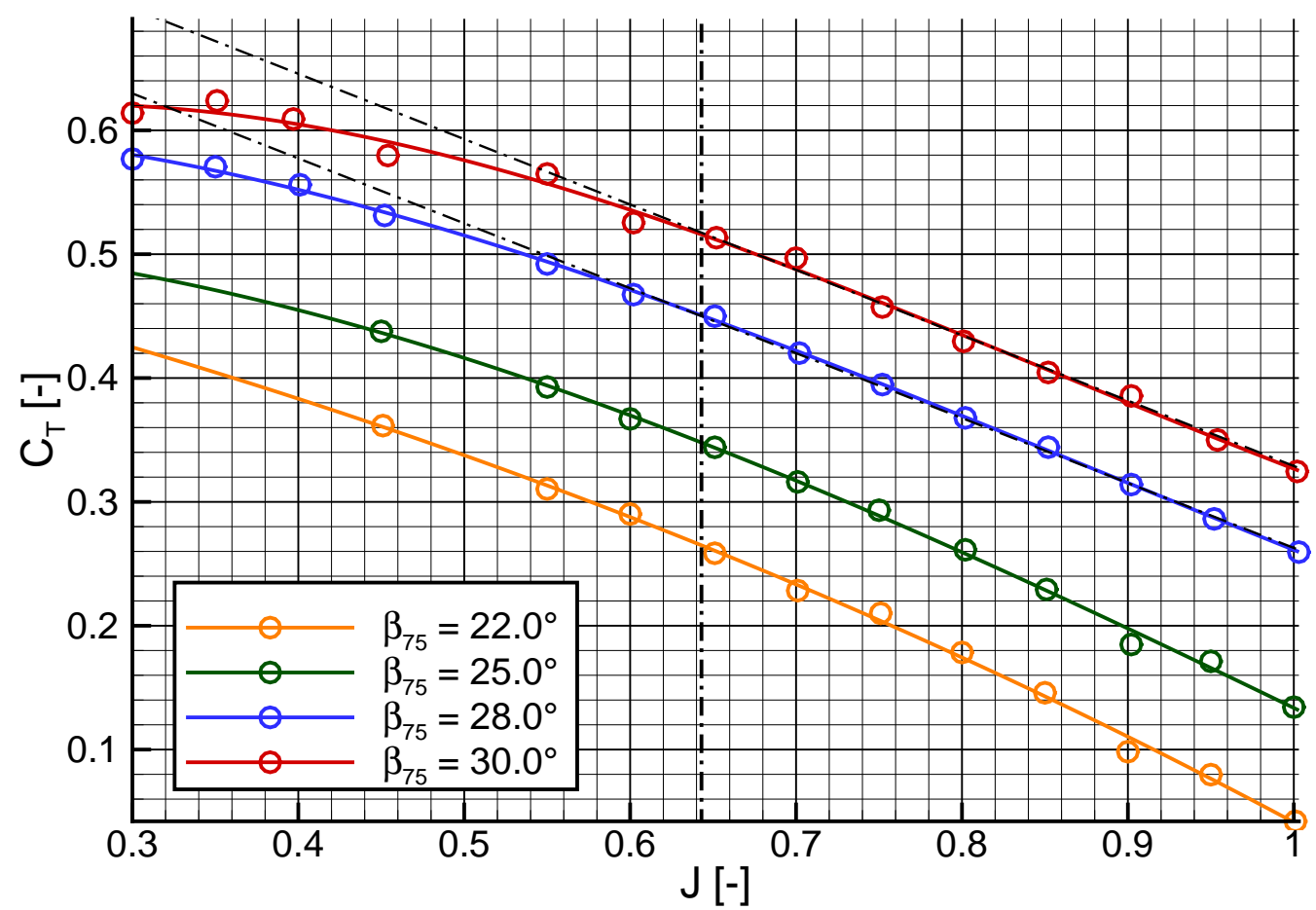

Figure 8. measured values for thrust coefficient $C_{T}$

The flow conditions for one blade segment $d r$ are depicted in figure 9 . Besides the delivered thrust $(d T)$ and torque $(d Q)$, the lift $(d L)$ and drag $(d D)$ forces per balde element are shown. All the delivered forces are influenced by the effecitve incoming flow velocity $v_{\text {eff }}$. This effective flow velocity is to be composed of the axial flow $v_{\infty}$, the rotational speed $\Omega \cdot r$ and the induced velocity $w_{i}$. The effective angle of attack for the specific blade element is the angle $\alpha$.

If induced velocities $w_{i}$ are not taken into account, the angle of attack of one blade element is defined through the axial and rotational velocity and the local pitch angle. As the advance ratio $\mathrm{J}$ is defined as

$$
J=\frac{v_{\infty}}{n \cdot D}
$$

it directly measures, together with the local pitch angle, the local angle of attack for the blade element. With increasing advance ratio $J$, the local angle of attack $\alpha$ decreases and vice versa. Therefore the particular blade elements are operating near their local lift maximum $c_{l_{\max }}$ for low andvance ratios. The tangential lines for $\beta_{75}=28^{\circ}$ and $\beta_{75}=30^{\circ}$ in figure 8 detach at different advance ratios, $J=0.64$ for $\beta_{75}=30^{\circ}$ and $J=0.60$ for $\beta_{75}=28^{\circ}$, from the linear slopes of the curves. This reveals, that the local angles of attack for a blade pitch angle of $\beta_{75}=30^{\circ}$ reach thier values for the local $c_{l_{\max }}$ at a higher advance ratio than they do for the lower blade pitch angle $\beta_{75}=28^{\circ}$. This behaviour is self-evident since the geometrical part of the local angles of attack is changed about $\Delta \beta_{75}=2^{\circ}$. As a consequence of the high blade load and the low advance ratios, a lift brakdown occurs due to the high local angles of attack on the blade. This phenomenon leads to the abandonment of the linear slopes of the curves for $C_{T}$ in figure 8. Since there is a shift in the advance ratio for the onset of the lift breakdown, for the lowest measured advance ratio of $J=0.3$, the difference between the sketched linear slope and the measured slope of the $C_{T}$ curve is larger for the higher blade pitch angle of $\beta_{75}=30^{\circ}$.

Figures 10 and 11 show the corresponding development of the power coefficient $C_{P}$ as well as the efficiency $\eta$ over the same range of advance ratios. Since the depicted bahaviour of the local blade segments for low advance ratios leads to a lift breakdown and not necessarily to a drag decrease, a less significant effect on the power coefficient can be observed than was found for the thrust coefficient. The overall development of the power coefficient is as expected. Due to the higher blade loads and thrust output, it increases with 


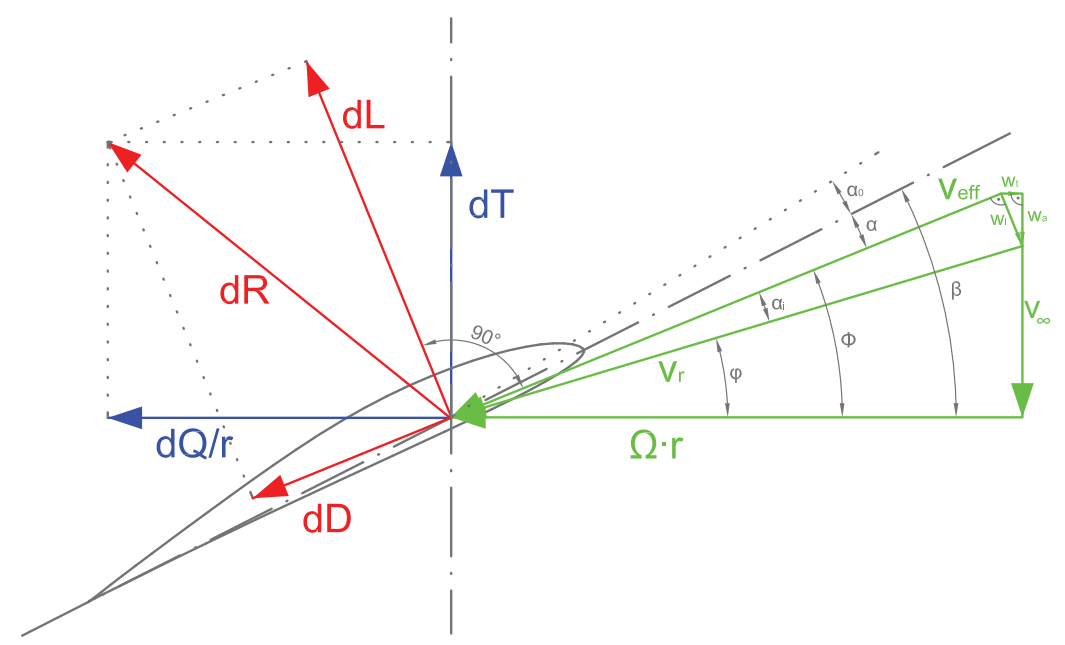

Figure 9. flow conditions at blade segment

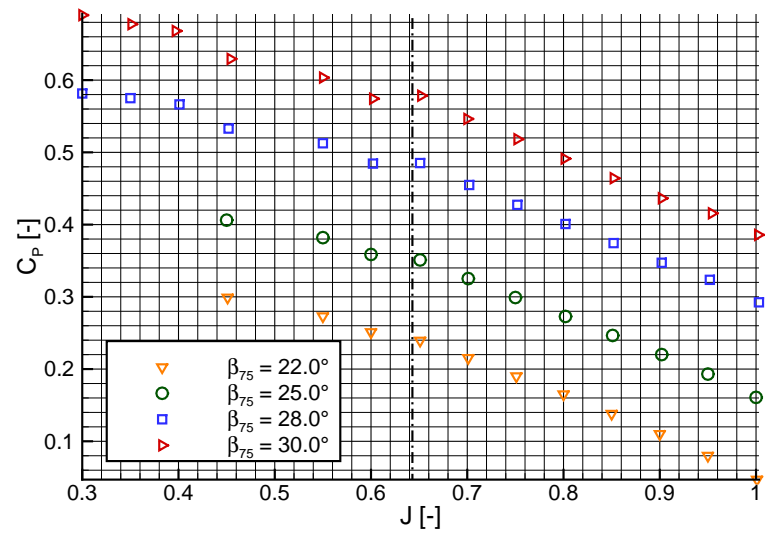

Figure 10. measured values for power coefficient $C_{P}$

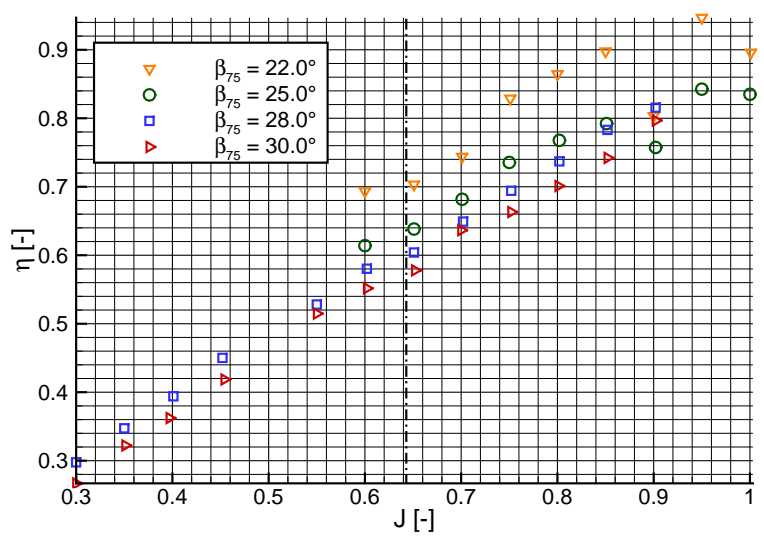

Figure 11. derived values for efficiency $\eta$, due to values depicted in figures 8,10

increasing blade pitch angle and decreasing advance ratios due to the higher angles of attack for the different blade segments.

Figure 11 shows the corresponding derived efficiency $\eta$. As $\eta$ connects the thrust and power coefficient linearly due to

$$
\eta=\frac{C_{T}}{C_{P}} \cdot J,
$$

and the values for $C_{T}$ and $C_{P}$ are of about the same size, small measurement inaccuracies might be amplified. This fact can be observed for eta at $J=0.9$ for the blade pitch angle of $\beta_{75}=25^{\circ}$ (green symbols). A closer look at the corresponding values for $C_{T}$ and $C_{P}$ revales a small shift of $C_{T}$ to lower values and a small shift of $C_{P}$ to higher values. Therefore the obtained value for the efficiency $\eta$ drifts apart. Despite these little inaccuracies, the values for $\eta$ develop as expected. The efficiency decreases with higher blade loads and therefore with increasing blade pitch angles and decreasing advance ratio.

To understand the phenomena that can be revealed from figure 12, the changes in operating conditions for one single blade on one rotation should be considered. During this rotation the blade shall be inclined in a positive manner with respect to the incoming flow. If the blade is in downward motion, a certain amount of the incoming flow velocity in direction of the roational component $(\Omega \cdot r$ see figure 9$)$ is added. The same 
amount is substracted while the blade is in upward motion. The vector addition yields an increase of local angle of attack for the blade in downward motion and vice versa for the blade in upward motion. This amount of change in local angle of attack is larger for the blade in downward motion. As another effect, the effective velocity $v_{\text {eff }}$ (see figure 9 ) towards the blade in downward motion and therefore the dynamic pressure is increased. Again, for the blade in upward motion yields the same but vice versa. The depicted changes in inflow conditions lead to an enlargement of the developed thrust of the whole propeller. For negative inclination angles of the propeller axis, the effects for down- und upmoving blade are considered to be similar but vice versa as described.

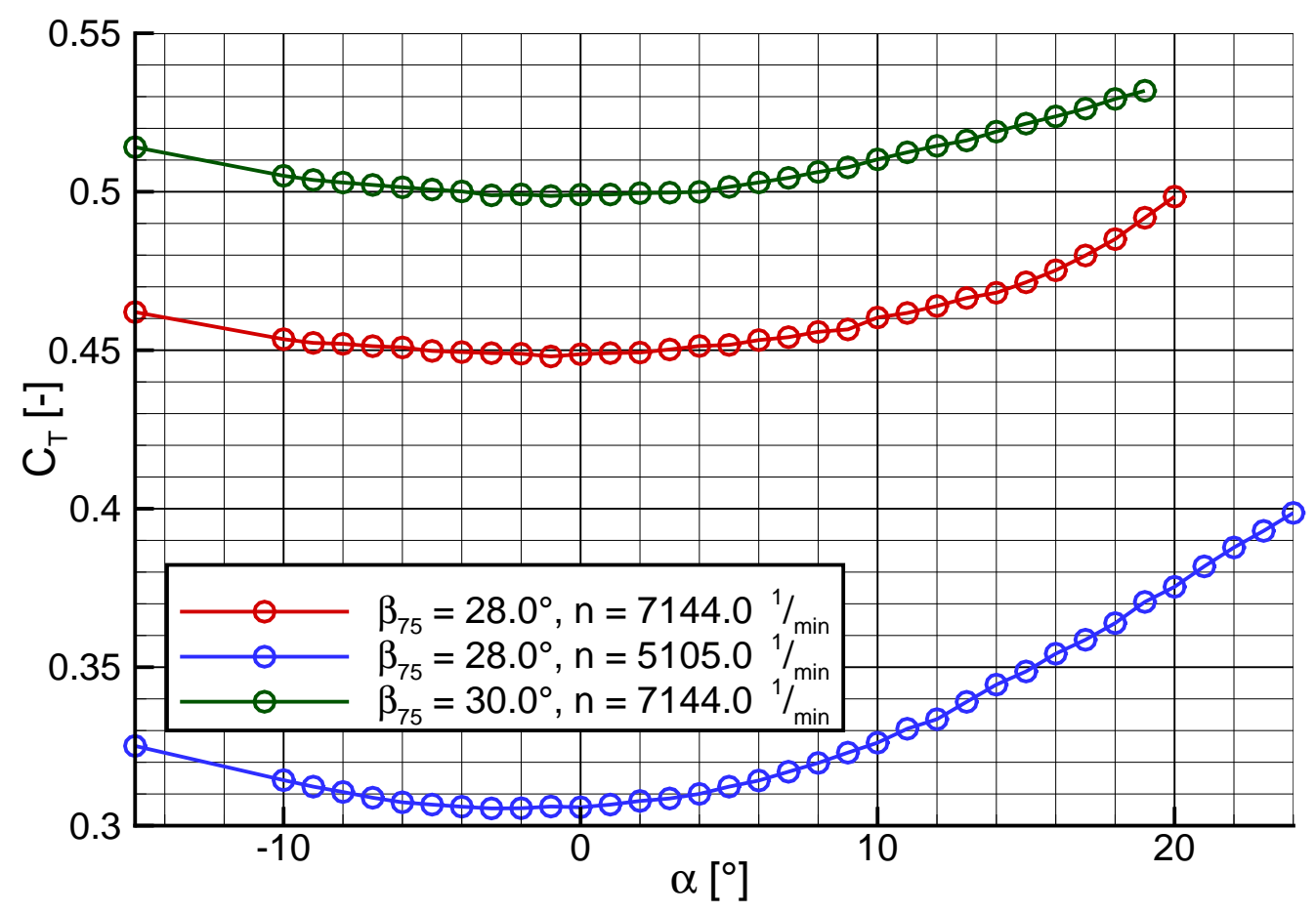

Figure 12. thrust coefficient $C_{T}$ over propeller axis inclination angle $\alpha$, all measurements taken at freestream velocity of $v_{\infty}=51.0 \mathrm{~m} / \mathrm{s}$

Figure 12 shows the development of the thrust coefficient $C_{T}$ on the vertical axis, over the propeller axis inclination angle $\alpha$ on the horizontal axis. Three different power settings are shown. As all curves are derived from measurements with a free stream velocity of $v_{\infty}=51.0 \mathrm{~m} / \mathrm{s}$, the difference between the conditon for the blue and the red curve is the advance ratio while the change from red to green is a different blade pitch angle. All three curves show a non-symmetric behaviour around the $\alpha=0^{\circ}$ position. For an uninstalled propeller this should not be the case. Therefore the obtained non-symmetric behaviour must be an effect of the installation of the propeller in front of the investigated high lift wing and the nacelle. Overall it can be stated, that the green and red curve show an almost constant offset over the range of investigated inclination angles, while the deflection of the curve for $\beta_{75}=28.0^{\circ}$ and $n=5105.01 / \mathrm{min}$ in blue, increases with increasing positive inclination angle. This larger increase of thrust with the angle of attack is a consequence of the lower rotational speed for this case in comparison with the other two cases. Thus the contribution of the in-plane velocity component due to the angle of attack plays a more dominant role in comparison with the rotational speed for this case $\left(\right.$ see also ${ }^{23}$ ).

The characteristics of the power coefficient $C_{P}$ with variable inclination angle are depicted in figure 13 in the same way as it is done for the thrust coefficient in the previous figure. The comparison of figure 12 with figure 13 reveals the same kind of development. Since with increasing thrust the local amount of lift increases, the corresponding amount of drag is increased as well. The drag of the blade sections transfers into the torque and therefore into the consumed power. The depicted changes in local blade forces have a stronger effect on the thrust coefficient than on the power coefficient. As an example, the thrust coefficient in figure 12 rises from $C_{T}=0.448$ to $C_{T}=0.498$ for a change in propeller axis inclination from $\alpha=0^{\circ}$ to $\alpha=20^{\circ}$ for the power setting $\beta_{75}=28^{\circ}$ and $n=7144.01 / \mathrm{min}$ (red curve). The corresponding change in power coefficient yields $C_{P}=0.485$ for $\alpha=0^{\circ}$ and $C_{P}=0.524$ for $\alpha=20^{\circ}$. By utilizing equation 2 
the matching values for the efficiency yield $\eta\left(\alpha=0^{\circ}\right)=0.594$ and $\eta\left(\alpha=20^{\circ}\right)=0.611$. This leads to the depicted development of the efficiency over the investigated range of propeller axis inclination (see figure $14)$.

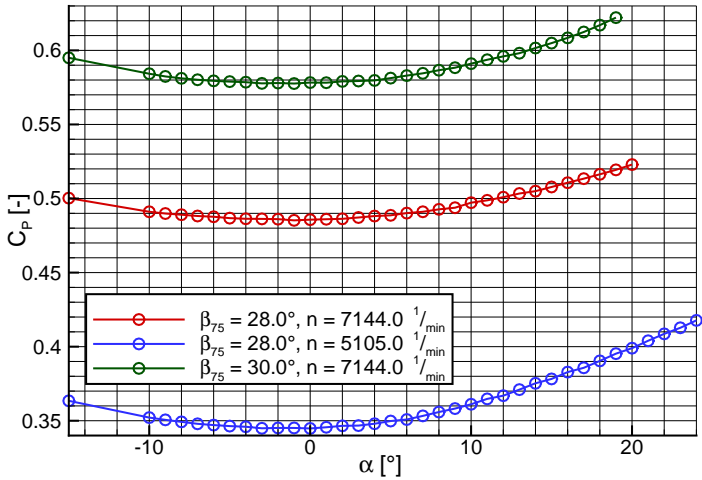

Figure 13. power coefficient $C_{P}$ over propeller axis inclination angle $\alpha$, all measurements taken at freestream velocity of $v_{\infty}=51.0 \mathrm{~m} / \mathrm{s}$

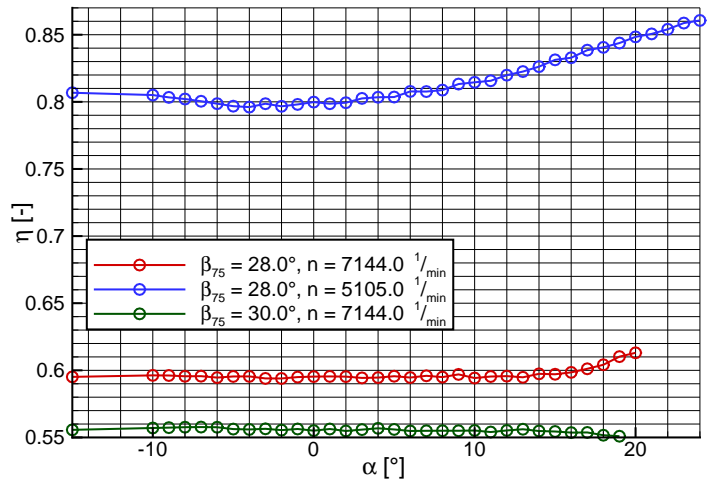

Figure 14. efficiency $\eta$ over propeller axis inclination angle $\alpha$ as derived from values in figures 12 and 13

\section{RANS computation of isolated Propeller}

\section{A. Numerical Setup}

The isolated propeller is analysed with the DLR Tau-Code. Tau is a software to solve the Reynolds-averagedNavier-Stokes (RANS) equations. The development of Tau was basically started in the German CFD (Computational Fluid Dynamics) project MEGAFLOW ${ }^{24}$ and is still under development by the $\mathrm{C}^{2} \mathrm{~A}^{2} \mathrm{~S}^{2} \mathrm{E}$ (Center for Computer Applications in Aerospace Science and Engineering) department of the DLR Institute of Aerodynamics and Flow Technology.

In case of the simulation of the BNF propeller a central finite volume scheme for the spatial discretization is used, whereas the discretization in the time domain is done by a Runge-Kutta scheme. For turbulence modeling a one-equation model by Spalart-Allmaras ${ }^{25}$ is used.

On the one hand the quality of the numerical solution depends on the used physical model and on the other hand on the resolution and quality of the used grids. The hybrid grids for the BNF propeller are generated with the commercial software Centaur ${ }^{26}$ developed by CentaurSoft. Centaur discretizes the analysed geometry surfaces e.g. with triangles. In order to correctly solve the boundary layer, a prismatic grid is attached to the surface triangles. This nearfield grid is generated so as to yield a non-dimensional wall distance of $y^{+}=1$ for the initial layer. The farfield is resolved by a tetrahedral grid. The different grid areas are displayed in figure 15.

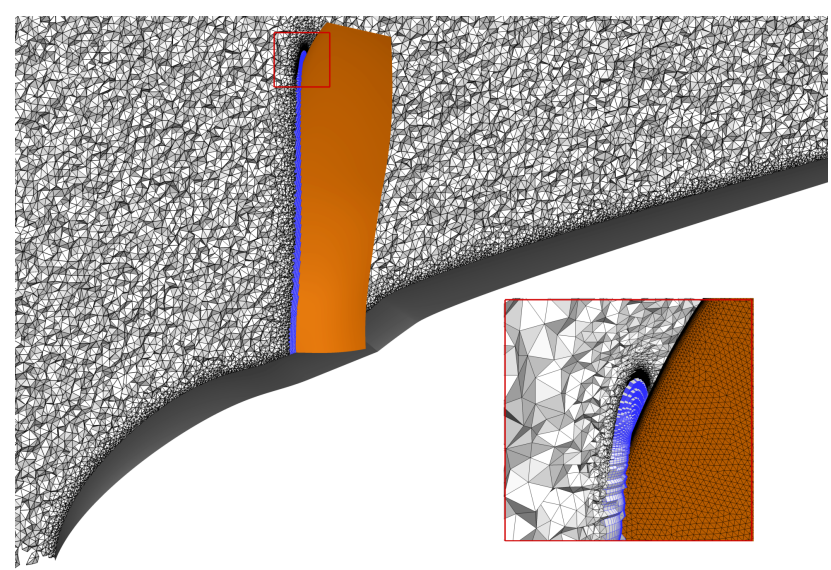

In order to reduce the mesh size, it is generated with utilisation of periodic boundary conditions. These special boundary conditions provided by the DLR Tau-Code allow for the simulation of the whole propeller by calculating the flow within only one angular segment, Figure 16 explains its functionality. The geometry in the red angular segment is the only part of the propeller and its farfield that is discretized by the computational grid as described above, periodicity is denoted by the blue arrow. The wake of the gridded blade acts as its own incoming flow. The utilisation of these periodic boundary condition prohibits investigations with non axial in-

Figure 15. grid setup for propeller simulation, nearfield mesh colored blue. 
coming flow direction. Despite the periodic boundary conditions, an inviscid boundary is used for the spinner and nancelle surface while a fully turbulent viscous boundary is applied to the blade surface. The declaration of the spinner and nacelle surface to be inviscid is necessary to avoid an unphysical rotating boundary layer.
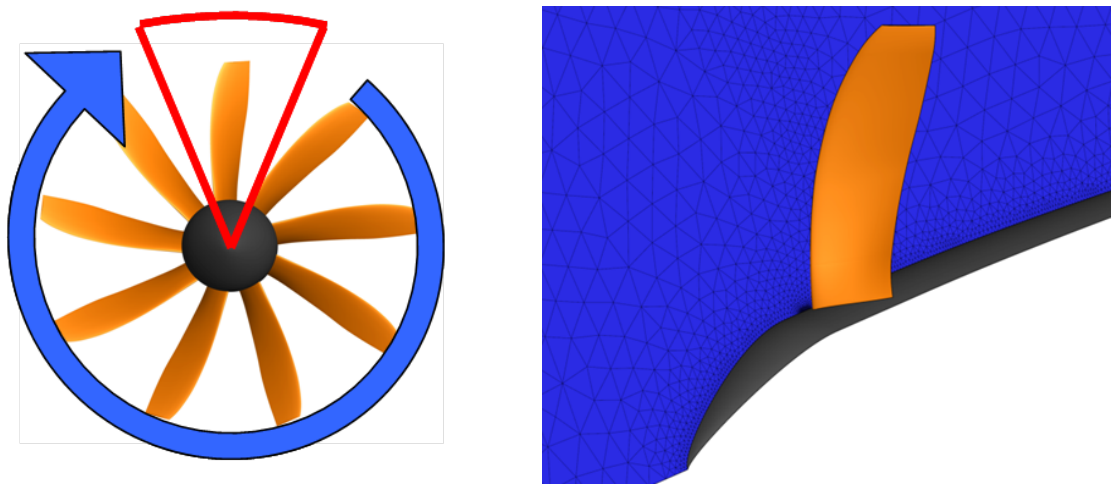

Figure 16. functionality of periodic boundary conditions in RANS-computations.

\section{B. Numerical Results and comparison with w/t data}

As figure 17 indicates, the whole propeller wake, meaning the wakes of all nine blades are caputured by the approach of simulating only one angular element as described in the previous section. The development of the propeller wake is shown by an iso surface of the vorticity.

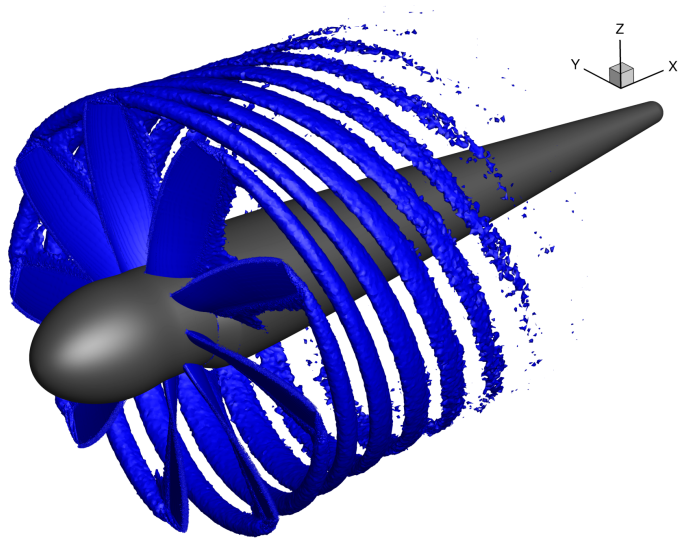

Figure 17. propeller wake, iso surface of vorticity

In order to gain insight into the capabilities of performance prediction, figure 18 shows the thrust coefficient $C_{T}$ on the vertical axis versus the advance ratio $J$ on the horizontal axis. Two different power settings according to two different blade pitch angles are presented, $\beta_{75}=28.0^{\circ}$ in red and $\beta_{75}=30.0^{\circ}$ in blue. The data obtained by BET is visualized with a dashed curve, while the RANS results are indicated by a solid curve and the $\mathrm{w} / \mathrm{t}$ measurements by symbols. In general it can be stated, that for both power settings, the $\mathrm{w} / \mathrm{t}$ measurements reveal the highest thrust output, followed by the BET and RANS results for a great range of advance ratios. The offset between measured thrust and the thrust obtained by the RANS computations is almost constant over the investigated range of advance ratios. The first and most obvious reason for this offset might be, that the $\mathrm{w} / \mathrm{t}$ data is not corrected in any way. But this missing correction cannot hold as the only reason for the obtained offset. Another reason is, that the data of the isolated propeller simulation is depicted versus data obtained from an installed configuration. Although the installation effects of the high lift wing on the propeller are reduced as much as possible during the w/t measurements, by setting the blowing coefficient for the active high lift system to zero and aligning the propeller axis to the incoming flow, they cannot be cancelled completly. Two installation effects connot be avoided via the described procedures. Although the active high lift system is switched off, the combination of wing and deflected flap still produces a certain amount of circulation that bends the flow in a manner, that the propeller experiences an upwash. The obtained effects are similar to the effects described for changes in propeller axis inclination and result in a higher thrust output. The second effect is a kind of blockage effect from the wing-flap-nacelle combination. This blockage effect leads to a reduced freestream velocity in vicinity of the propeller and therefore to reduced advance ratios. This phenomenon again leads to higher thrust outputs. Since the depicted thrust coefficients are obtained under the same freestream velocities (see table 5), for both power settings the obtained offset between RANS and $\mathrm{w} / \mathrm{t}$ data is nearly identical. Besides this a very good agreement in the slopes of the $\mathrm{w} / \mathrm{t}$ measured thrust and the thrust of the RANS computations with respect to advance ratio can be found. 
Similiarly, a good correlation with the slope of the BET computed thrust development is seen for most of the investigated advance ratios. At a certain advance ratio, the BET fails as three dimensional effects cannot be taken into account. These three dimensional effects lead to a decrease in boundary layer thickness for the rotating propeller blades and therefore to a lift breakdown of the two dimensional airfoil data the BET relies on. As a proof of this hypothesis, it can bee seen that the point in $J$ at which the BET predicts a thrust breakdown is shifted towards higher advance ratios for the higher blade pitch angle. This behaviour is expected since, the airfoils for a blade pitch angle of $\beta_{75}=30^{\circ}$ operate closer to their individual maximum lift coefficient than they do for $\beta_{75}=28^{\circ}$.

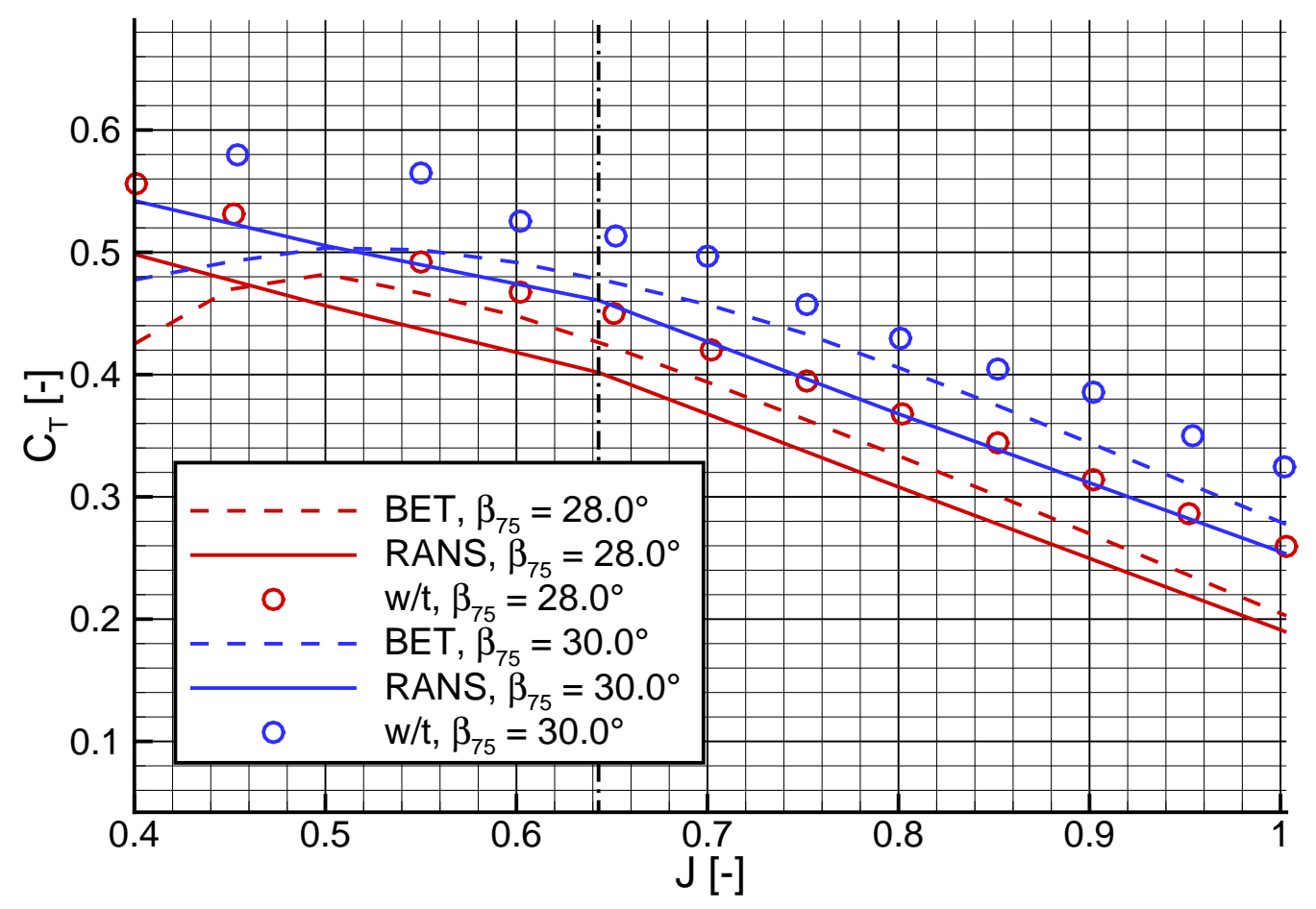

Figure 18. thrust coefficient $C_{T}$ over advance ratio $J$ and comparison with RANS and BET data

As described in section III one propeller blade is equipped with time accurate pressure taps at the positions listed in table 4. Figure 19 shows six pressure distributions for the radial stations at which the time accurate pressure taps are positioned. The depicted dimensionless pressure coefficient is defined as

$$
c_{p, r o t}=\frac{p-p_{\infty}}{\rho \cdot n^{2} \cdot D^{2}} .
$$

The red frame in figure 19 enlarges the data on the suction side of the airfoil around the probe data, while the blue frame does for the pressure side. As the time accurate measured data is compared to simulation data that is steady in time, the maximum, minimum and mean value for every pressure probe is depicted. The deviance between measured mean value and the simulation result is rather small and for all six pressure probes the simulation result lies within the measured maximum and minimum. This fact leads to the assumption, that besides the deviations in performance data, the flow around the propeller is well predicted by the chosen RANS approach.

\section{Conclusions}

Within the German research project "Bürgernahes Flugzeug" a propeller for a future QESTOL aircraft is designed and investigated via $\mathrm{w} / \mathrm{t}$ measurements and RANS-simulations. The propeller is mounted in front of a semispan wing that is equipped with an active gapless high lift system and driven by an electric motor. The obtained propeller performance is analyzed by means of $\mathrm{w} / \mathrm{t}$ measurement data in comparison 


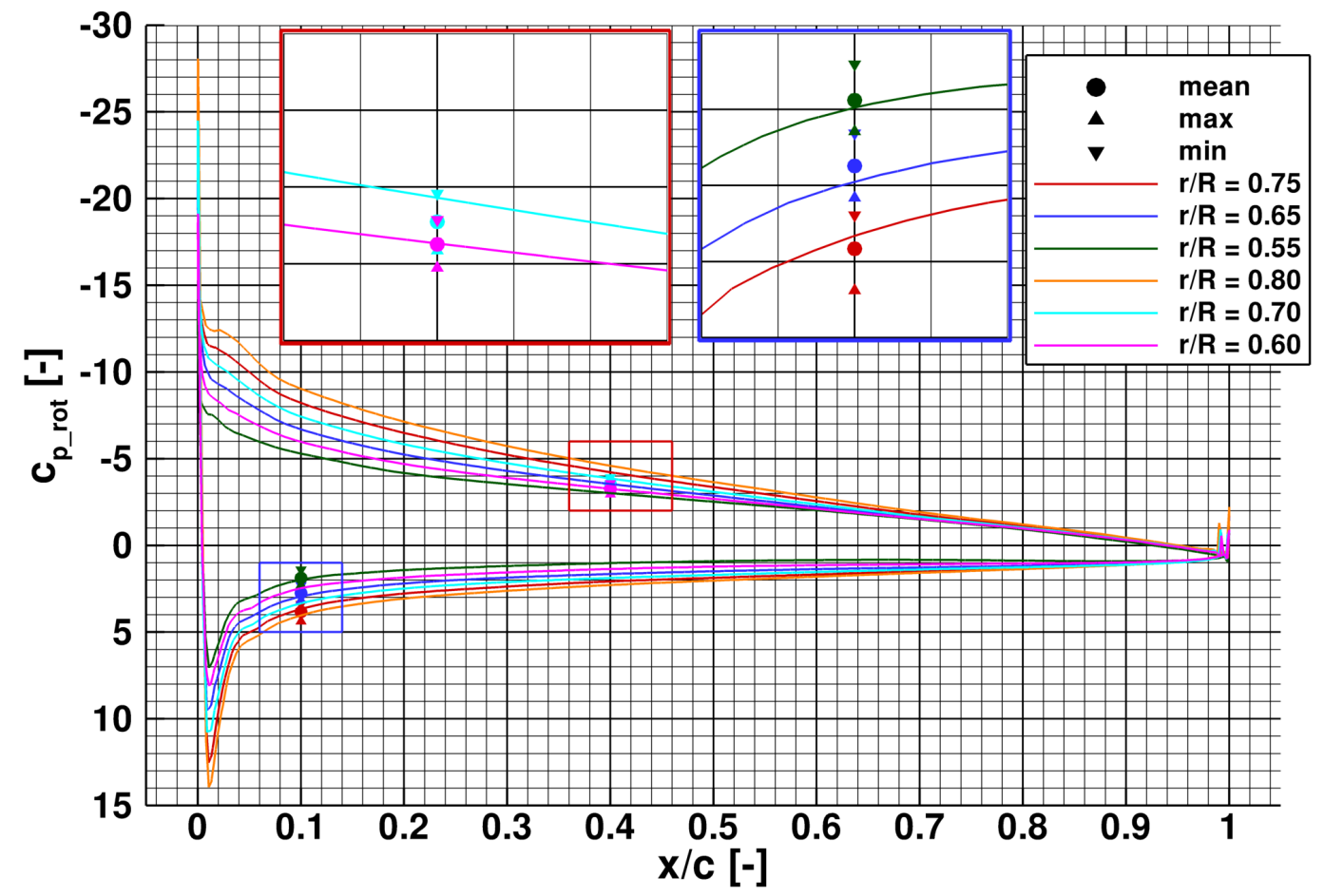

Figure 19. pressure coefficient $c_{p, r o t}$ for different airfoil sections of the propellerblade comparison with measured data

with simulation results. In addition, the propeller behaviour as influenced by some installation effects and propeller axis inclination is discussed. The propeller performs as predicted during the $\mathrm{w} / \mathrm{t}$ tests and it can be stated, that the chosen RANS approach seem feasible to predict the propeller performance.

\section{Acknowledgments}

The work presented in this paper was carried out in the project "Bürgernahes Flugzeug" which was established in 2009 and is partly funded by the german federal state of Lower Saxony. The authors would like to thank the team of DNW-NWB for thier great support during the conducted w/t campaigns. Furthermore the authors like to express their gratitude to Prof. Leo Veldhuis and Prof. Georg Eitelberg of the Faculty of Aerospace Engineering of the Delft University of Technology for supporting the master thesis of Ruud F. Janssen that contributed the RANS simulation data.

\section{References}

${ }^{1}$ Airbus S.A.S., "Global Market Forecast 2011-2030," Airbus, Blagnac, France, 2011.

${ }^{2} \mathrm{ICAO}$ - International Civil Aviation Organisation, "Outlook for Air Transport to the Year 2025," ICAO, Bonn, Germany, 2007.

${ }^{3}$ E. Grunewald, P. Berster, G. Bischoff, M. Gelhausen, W. Grimme, M. Hepting, A. Leipold, S. Maertens, "Luftverkehrsbericht 2008/2009 - Daten und Kommentierungen des deutschen und weltweiten Luftverkehrs," DLR, German Aerospace Center, IB-126-2010-1, Cologne, Germany, 2010.

${ }^{4}$ Wegner, A. and Marsh, D., "A Place to Stand: Airports in the European Air Network," Vol. 3, STATFOR, 2007.

${ }^{5}$ R. Henke, T. L. and Anton, E., "Impact of an Innovative Quiet Regional Aircraft on the Air Transportation System," Journal of Aircraft, Vol. 47, No. 3, 2010, pp. 875-886.

${ }^{6}$ Plate, R., "Entwurf und Optimierung eines Verkehrsflugzeugs mit Propellerantrieb für den Einsatz von kleinen Flugplätzen," Studienarbeit Nr. 796, 2009.

${ }^{7}$ Lenfers, C., "Propeller Design for a future QESTOL Aircraft in the BNF Project," AIAA 2012-3334, 2012.

${ }^{8}$ Department of Defence, Dictionary of Militray and Associated Terms, Joint Publication 1-02, 2001.

${ }^{9}$ Englar, R. and Huson, G. G., "Development of Advanced Circulation Control Wing High-Lift Airfoils," Journal of Aircraft, Vol. 21, No. 7, 1984. 
${ }^{10}$ C. Jensch, K. C. Pfingsten, R. Radespiel, "Numerical Investigation of Leading Edge Blowing and Optimization of the Slot Geometry for a Circulation Control Airfoil," Numerical Fluid Mechanics VII, Springer Verlag, 2010.

${ }^{11}$ Hepperle, M., "Ein Computerprogramm für Entwurf und Analyse von Propellern," diploma thesis, Insitute of Aircraft Design, University of Stuttgart, 1984.

12 Adkins, C. N., "Design of Optimal Propellers," AIAA 83-0190, 1983.

${ }^{13}$ Larrabee, E. E., "Practical Design of Minimum Induced Loss Propellers," SAE-Paper 790585, 1979.

${ }^{14}$ Himmelskamp, H., "Profile Investigations on a Rotating Airscrew," AVA 45 A 20, Aerodynamische Versuchsanstalt Goettingen, 1947.

${ }^{15}$ Gur, O. and Rosen, A., "Propeller Performance at Low Advance Ratio," Journal of Aircraft, Vol. 42, No. 2, 2005, pp. $435-441$.

${ }^{16}$ Beck, N. and Radespiel, R., "Entwurf eines Windkanalexperiments fuer aktiven Hochauftrieb," Deutscher Luft- und Raumfahrtkongress, 161294, 2010.

${ }^{17}$ N. Beck, M. Wentrup, R. Radespiel, "Realisierung eines Windkanalexperiments fuer aktiven Hochauftrieb," Deutscher Luft- und Raumfahrtkongress, 241373, 2011.

${ }^{18}$ Rüdiger, S., Lenfers, C. and Friedrichs, J., "Antrieb und Messtechnik für einen Propeller an einem Windkanalmodell," Deutscher Luft- und Raumfahrtkongress, 2011.

${ }^{19}$ A.Rezaeian, "Dynamic Stability Analysis of a Propeller-Wing Wind Tunnel Model," Deutscher Luft- und Raumfahrtkongress, 2011.

${ }^{20}$ A.Rezaeian, "Whirl Flutter Analysis of a Wind Tunnel Model Using Multidisciplinary Simulation and Multibody Dynamics," 37th European Rotorcraft Forum, Italy, 2011.

${ }^{21}$ A.Rezaeian, "Stability Assessment of a Propeller-Wing Wind Tunnel Model based on Analysis using measured Structural Data and Online-Monitoring," to be published at International Forum on Aeroelasticity and Structural Dynamics, Bristol, UK, 2013.

${ }^{22}$ N. Beck, R. Radespiel, C. Lenfers, J. Friedrichs, A. Rezaeian, "Aerodynamic effects of propeller slipstream on a wing with circulation control by internally blown flaps," to be published at AIAA SciTech Conference, 2014.

${ }^{23}$ L. Veldhuis, E. van Berkel, M. Kotsonis, G. Eitelberg, "Non-Uniform Inflow Effects on Propeller Performance," 31st AIAA Applied Aerodynamics Conference, AIAA 2013-2801, 2013.

${ }^{24}$ Gerold, T., "Overview of the Hybrid RANS Code TAU," MEGAFLOW - Numerical Flow Simulation for Aircraft Design, edited by N. Kroll and J. Fassbender, Vol. 89, Notes on Numerical Fluid Mechanics and Multidisciplinary Design, Springer, 2005.

${ }^{25}$ Spalart, P. and Alamaras, S., "A One-Equation Turbulence Model for Aerodynamic Flows," AIAA 92-0439, 1992.

${ }^{26}$ CentaurSoft, http://www.centaursoft.com, web page, 2013. 